\title{
Swift heavy-ion irradiation-induced shape and structural transformation in cobalt nanoparticles
}

\author{
D. J. Sprouster, ${ }^{1, a)}$ R. Giulian, ${ }^{1}$ L. L. Araujo, ${ }^{1}$ P. Kluth, ${ }^{1}$ B. Johannessen, ${ }^{2}$ D. J. Cookson, ${ }^{2}$ \\ and M. C. Ridgway ${ }^{1}$ \\ ${ }^{1}$ Department of Electronic Materials Engineering, Research School of Physics and Engineering, \\ Australian National University, Canberra, Australian Capital Territory 0200, Australia \\ ${ }^{2}$ Australian Synchrotron, Clayton, Victoria 3168, Australia
}

(Received 6 January 2011; accepted 4 April 2011; published online 1 June 2011)

\begin{abstract}
The shape and structural evolution of Co nanoparticles embedded in $\mathrm{SiO}_{2}$ and subjected to swift heavy-ion irradiation have been investigated over a wide energy and fluence range. Modifications of the nanoparticle size and shape were characterized with transmission electron microscopy and small-angle x-ray scattering. Nanoparticles below a threshold diameter remained spherical in shape and progressively decreased in size under irradiation due to dissolution. Nanoparticles above the threshold diameter transformed into nanorods with their major dimension parallel to the incident ion direction. Modifications of the atomic-scale structure of the Co nanoparticles were identified with $\mathrm{x}$-ray absorption spectroscopy. Analysis of the x-ray absorption near-edge spectra showed that prior to irradiation all Co atoms were in a metallic state, while after irradiation Co atoms were in both oxidized and metallic environments, the former consistent with dissolution. The evolution of the nanoparticle short-range order was determined from extended $\mathrm{x}$-ray absorption fine structure spectroscopy. Structural changes in the Co nanoparticles as a function of ion fluence included an increase in disorder and asymmetric deviation from a Gaussian interatomic distance distribution coupled with a decrease in bondlength. Such changes resulted from the irradiation-induced decrease in nanoparticle size and subsequent dissolution. (ㅇ 2011 American Institute of Physics. [doi:10.1063/1.3587171]
\end{abstract}

\section{INTRODUCTION}

Metallic and semiconductor nanoparticles (NPs) exhibit novel size-dependent structural, electronic, magnetic, and optical properties that differ significantly in comparison to those of isolated atoms, surfaces, and their bulk counterparts. Such differences stem from the non-negligible influence of surface atoms and/or quantum confinement of charge carriers. The advantageous properties of NP-based materials have made them the focus of an intensive research effort in a range of scientific disciplines. In particular, the drive for further miniaturization of electronic, magnetic, and photonic devices has led to considerable experimental and theoretical effort to understand NP properties with an emphasis on the effects of size, shape, and host matrix (for example, see Refs. 1-3).

Ion irradiation is a flexible technique for the modification of NP size, shape, and structure and, hence, can be utilized to tune or tailor NP properties. As an ion passes through a solid, energy is lost via interactions with target nuclei (nuclear energy loss $\left(S_{n}\right)$ ) and target electrons (electronic energy loss $\left(\mathrm{S}_{\mathrm{e}}\right)$ ). In the low-energy ion irradiation (LEII) regime, collisions with target nuclei can produce atomic displacements and recoils which can then yield collision cascades. In crystalline elemental semiconductors ${ }^{4,5}$ and some ceramics, ${ }^{6}$ LEII can result in the formation of amorphous zones/clusters ${ }^{7}$ and the accumulation of such zones

\footnotetext{
a) Author to whom correspondence should be addressed. Electronic mail: djs109@physics.anu.edu.au.
}

can produce the amorphous phase. In metallic NPs, LEII effects include the formation of an amorphous phase ${ }^{8-10}$ not readily achievable in bulk metals and the modification of both the NP size and spatial distribution. ${ }^{11}$

In the swift heavy-ion irradiation (SHII) regime, ionization and electronic excitation processes are dominant. Two models have been proposed to explain the formation of ion tracks and SHII-induced damage: the "Coulomb explosion"12,13 and "thermal spike"14,15 models. The former is based on the electrostatic repulsion between ions generated in the wake of the incident projectile that can lead to atomic displacements. In contrast, for the latter, energy is transferred to the lattice via electron-phonon coupling and the resulting rapid increase in local temperature (or thermal spike) can yield a molten ion track of several nanometers in diameter. ${ }^{16}$ Examples of materials modification using SHII include the anisotropic plastic deformation of glasses, ${ }^{17} \mathrm{a}$ monoclinic-to-tetragonal phase transformation in bulk oxides $^{18}$ and a crystalline-to-amorphous phase transformation in bulk semiconductors ${ }^{19,20}$ and insulators. ${ }^{21}$ Examples of SHII effects in metallic NPs include the partial amorphization of $\mathrm{Bi} \mathrm{NPs},{ }^{22}$ the fcc-to-hcp phase transformation in $\mathrm{Co} \mathrm{NPs}{ }^{23}$ and the spherical-to-faceted transformation in $\mathrm{Au}$ $\mathrm{NPs}^{24}$ Furthermore, SHII induces a spherical-to-rodlike shape transformation in metallic NPs embedded in amorphous $\mathrm{SiO}_{2}$ (Refs. 25-35) with the NP elongation aligned parallel to the incident ion direction. Unlike embedded NPs, freestanding $\mathrm{Ag}$ and $\mathrm{Au}$ NPs showed no deformation after $\mathrm{SHII}^{34,36}$ indicative that the deformation process necessitates the presence of the $\mathrm{SiO}_{2}$ matrix. A definitive theory for the 
shape transformation has yet to be established and, furthermore, there has been little experimental work reporting on the effects of SHII on the structural evolution of metallic NPs.

Co NPs have attracted significant attention due to their size, shape, and crystallographic-dependent magnetic properties, ${ }^{37}$ with particular attention on the evolution of the magnetic properties with NP shape for applications in biomedicine ${ }^{38}$ and magnetic storage technology. Nonspherical Co nanorods and nanowires exhibit unique perpendicular magnetic anisotropy, coercivity, remanence, and activation volumes that are heavily dependent on the nanorod major diameter. ${ }^{39}$ Novel methods to tailor and control the shape of Co NP ensembles are thus of paramount importance if they are to be successfully implemented into future magnetic devices. Here we present results for the influence of SHII on the shape and structure of Co NPs in $\mathrm{SiO}_{2}$ formed by ion implantation and thermal annealing. The data presented here extends that of D'Orleans et al..$^{25,40-42}$ as we identify various $\mathrm{S}_{\mathrm{e}}$-dependent shape and structural changes demonstrating the usefulness of SHII as a method of fabricating aligned, elongated NPs with specific dimensions and structure. The evolution of the NP shape and structure was characterized as a function of the ion irradiation energy and fluence by cross-sectional transmission electron microscopy (XTEM), small-angle $\mathrm{x}$-ray scattering (SAXS), and $\mathrm{x}$-ray absorption spectroscopy (XAS).

\section{EXPERIMENT}

Co NPs were prepared by the implantation of Co ions into $2 \mu \mathrm{m}$ thick $\mathrm{SiO}_{2}$ layers thermally grown on $\mathrm{Si}(100)$ substrates, with all implantations performed at liquid $\mathrm{N}_{2}$ temperature. Multiple energy $(0.75,1.00$, and $1.40 \mathrm{MeV})$ and multiple fluence $\left(4.4,4.8\right.$, and $\left.10.6 \times 10^{16} \mathrm{~cm}^{-2}\right)$ implantations resulted in a nearly constant Co concentration of 3.0 at. $\%$ over a depth range of $0.75-1.40 \mu \mathrm{m}$. Samples were subsequently annealed in flowing forming gas for $1 \mathrm{~h}$ at a temperature of $1100{ }^{\circ} \mathrm{C}$ to induce precipitation and NP growth. The average volume-weighted spherical NP diameter was $12.0 \pm 4.3 \mathrm{~nm}$ as determined from SAXS analysis (discussed below). Samples were then irradiated at room temperature and normal incidence with ${ }^{197} \mathrm{Au}$ ions at 27,89 , or $185 \mathrm{MeV}$ over a fluence range of $10^{12}-10^{14} \mathrm{~cm}^{-2}$. The electronic and nuclear stopping powers of $\mathrm{Au}$ in both $\mathrm{SiO}_{2}$ and $\mathrm{Co}$, as calculated by TRIM, ${ }^{43}$ are listed in Table I. The projected range of the $\mathrm{Au}$ ions was well beyond the NP distribution and, thus, impurity effects were negligible.

The NP shape and size were characterized with XTEM and SAXS, respectively. XTEM samples were prepared by

TABLE I. Parameters for Au ions in $\mathrm{SiO}_{2}$ and Co calculated by TRIM. ${ }^{43}$

\begin{tabular}{lccccc}
\hline \hline $\begin{array}{l}\text { Energy } \\
(\mathrm{MeV})\end{array}$ & $\begin{array}{l}\text { Range } \\
(\mu \mathrm{m})\end{array}$ & $\begin{array}{l}\mathrm{S}_{\mathrm{e}} \mathrm{SiO}_{2} \\
(\mathrm{keV} / \mathrm{nm})\end{array}$ & $\begin{array}{l}\mathrm{S}_{\mathrm{e}} \mathrm{Co} \\
(\mathrm{keV} / \mathrm{nm})\end{array}$ & $\begin{array}{l}\mathrm{S}_{\mathrm{n}} \mathrm{SiO}_{2} \\
(\mathrm{keV} / \mathrm{nm})\end{array}$ & $\begin{array}{l}\mathrm{S}_{\mathrm{n}} \mathrm{Co} \\
(\mathrm{keV} / \mathrm{nm})\end{array}$ \\
\hline 27 & 6.3 & 4.8 & 9.4 & 0.7 & 2 \\
89 & 13 & 12.7 & 29.8 & 0.3 & 0.9 \\
185 & 19.2 & 17.6 & 45.1 & 0.2 & 0.5 \\
\hline \hline
\end{tabular}

conventional mechanical grinding and ion beam thinning. Bright-field images and electron diffraction patterns were acquired using a Phillips CM300 microscope operating at $300 \mathrm{kV}$. Transmission SAXS measurements were performed at beamline 15ID-D of the Advanced Photon Source using $11.27 \mathrm{keV}$ x-rays (1.1 ^ wavelength). The elongated NP samples were carefully aligned with the photon beam to yield an isotropic scattering pattern. The scattering intensity was collected for $5 \mathrm{~s}$ at a camera length of $1871 \mathrm{~mm}$. A scattering spectrum from an unimplanted $\mathrm{SiO}_{2}$ layer was subtracted from all NP spectra. The maximum entropy method ${ }^{44}$ was used to determine the distribution of NP widths.

Fluorescence-mode $\mathrm{X}$-ray absorption near edge structure (XANES) and extended $\mathrm{x}$-ray absorption fine structure (EXAFS) measurements were performed at beamline 20-B of the Photon Factory (Japan). Spectra were measured at the Co $K$-edge $(7.709 \mathrm{keV})$ with the temperature maintained at $15 \mathrm{~K}$ to minimize thermal vibrations. Data were collected to a photoelectron wavenumber $(k)$ value of $17 \AA^{-1}$. Background subtraction, spectra alignment, and normalization of the EXAFS data were performed in ATHENA. ${ }^{45}$ The position of the Co edge was determined from the maximum of the first derivative of the absorption spectra. The isolated EXAFS signal was then Fourier transformed (FT) over a $k$ range of 3.0-15.0 $\AA^{-1}$ with an adaptive Hanning window and back FT over a phase-corrected radial distance $(R)$ range of 1.6-2.7 $\AA$ to isolate the first nearest neighbor peak. Structural parameters were refined in ARTEMIS ${ }^{45}$ utilizing the IFEFFIT $^{46}$ code through a nonlinear least squares fit to the experimental data with multiple $k$-weights of $1-4$ to reduce inter-parameter correlation. Effective phase shifts and scattering amplitudes were calculated $a b$ initio with the FEFF8 code (version 8.1). ${ }^{47}$ The energy shift parameter $\left(E_{0}\right)$ and amplitude reduction factor $\left(S_{0}^{2}\right)$ were determined from a bulk standard and then fixed for subsequent fitting of all NP spectra. The coordination number $(C N)$ was set to 12 for the bulk standards but allowed to float for the NP samples. The bondlength $(B L)$, Debye-Waller factor $(D W F)$, and third cumulant $\left(C_{3}\right)$ were allowed to vary during the fitting process for both bulk and NP samples.

\section{RESULTS}

\section{A. Size and shape}

Figure 1 shows bright-field XTEM images and corresponding minor and major dimension distributions for the Co NPs before and after $89 \mathrm{MeV}$ SHII. The figure demonstrates that spherical Co NPs have transformed into nanorods along the incident ion direction, consistent with previous studies. $^{25,40}$ The elongation process is clearly cumulative with samples requiring fluences greater than $10^{13} \mathrm{~cm}^{-2}$ (or equivalently hundreds of overlapping impacts for an ion track of diameter $10 \mathrm{~nm}$ ). Included in Fig. 1(f) is a high magnification XTEM micrograph showing a number of smaller spherical satellite NPs surrounding an elongated NP. Figures $1(\mathrm{~d}), 1(\mathrm{f})$, and $1(\mathrm{~h})$ show that the minor dimension distributions determined from the XTEM analysis become progressively narrower and are Gaussian in shape. The major 

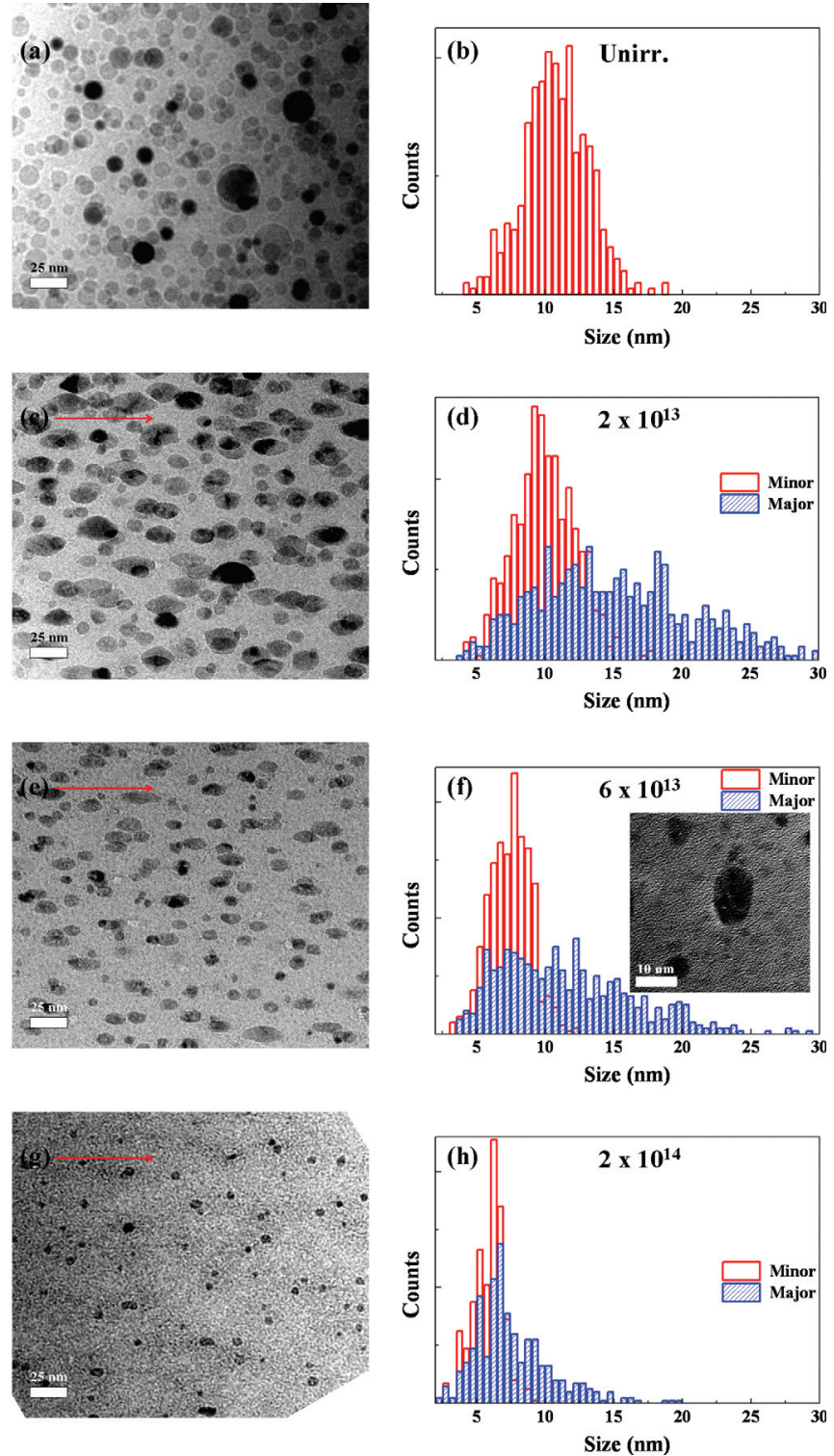

FIG. 1. (Color online) Bright field XTEM micrographs ((a), (c), (e), (g)) and corresponding size distributions ((b), (d), (f), (h)) as a function of fluence $\left(\mathrm{cm}^{-2}\right)$ for Co NPs subjected to $89 \mathrm{MeV}$ Au ion irradiation. Arrows in $((\mathrm{c}),(\mathrm{e}),(\mathrm{g}))$ show the direction of irradiation.

dimension distributions, however, are considerably broader and lognormal in form. The evolution of the minor dimension as a function of the major dimension, as determined from XTEM, for the $89 \mathrm{MeV}$ sample set is shown in Fig. 2. Each point in Fig. 2 represents the mean value of the minor dimension for a given major dimension $( \pm 1 \mathrm{~nm})$ from a measurement of $\sim 600$ NPs at each fluence. Figure 2 demonstrates that there is a threshold or minimum size for elongation of $\sim 6.5 \mathrm{~nm}$ for $89 \mathrm{MeV} \mathrm{Au}$ ion irradiation. NPs larger than this threshold diameter elongate with ion fluence and the minor dimension eventually saturates at approximately the same value as the threshold for shape transformation. The greatest aspect ratios were observed at intermediate fluences. The aspect ratio decreased, due to NP dissolution, for fluences beyond $6 \times 10^{13} \mathrm{~cm}^{-2}$.

Complementary determinations of the nanorod minor dimension was achieved via SAXS. Figure 3(a) shows the

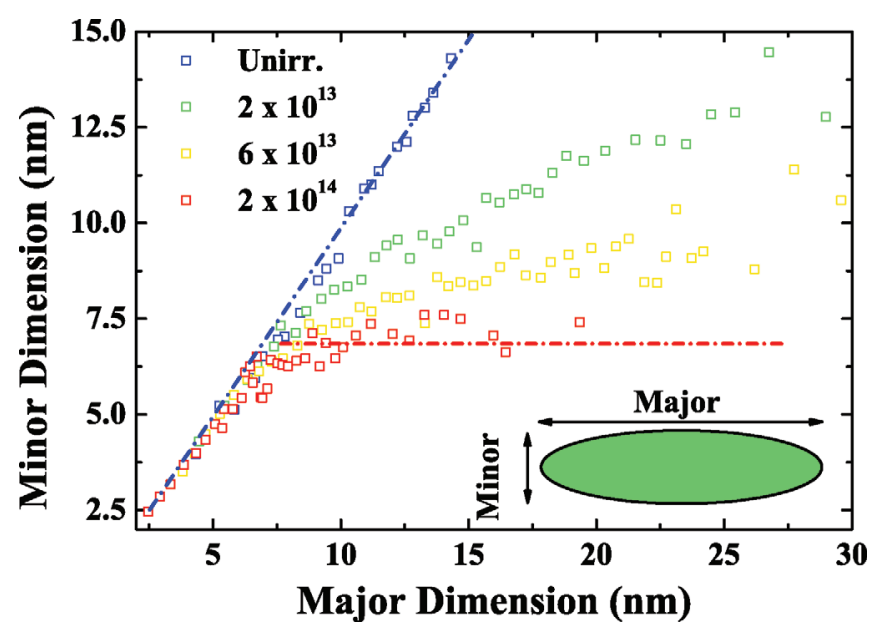

FIG. 2. (Color online) NP minor dimension as a function of major dimension for $89 \mathrm{MeV} \mathrm{Au}$ ion irradiation at different fluences $\left(\mathrm{cm}^{-2}\right)$

background-corrected scattering intensity for Co NPs as a function of the scattering vector $\mathrm{Q}$ following $89 \mathrm{MeV} \mathrm{Au}$ ion irradiation. The oscillations in the scattering intensity at high fluences are indicative of a narrowing of the minor dimension distribution ${ }^{48}$ with the reconstructed distributions shown in Fig. 3(b). The size distributions determined from both XTEM and SAXS for the unirradiated sample are superimposed in the inset of Fig. 3(b) for comparison, and good agreement is readily apparent. A decrease in intensity is observed at the highest ion fluence and is indicative of NP dissolution as discussed in the following section. Similar trends were observed for all irradiation energies. The narrowing of the minor dimension distribution with increasing ion fluence is consistent with the XTEM analysis. NPs with diameter $<5 \mathrm{~nm}$ were not apparent prior to irradiation but appear thereafter as the small spherical satellite NPs in XTEM images (Fig. 1(f)). The size distribution of these very small NPs is most easily quantified with SAXS (Fig. 3(b)), which probes a much larger volume of the sample relative to the statistically limited XTEM analysis.

The saturation of the minor dimension extracted from XTEM images is plotted in Fig. 4 as a function of the Au ion electronic stopping power in $\mathrm{SiO}_{2}$. For comparison, our determination of the diameter of the ion track in $\mathrm{SiO}_{2}$ is also included. ${ }^{49}$ The saturation value of the minor dimension decreases with decreasing SHII energy and is, within experimental error, less than or equal to the ion track diameter. These results suggest metallic NP elongation is confined by the ion track, consistent with recent studies for a variety of different metals. ${ }^{50}$

D'Orleans et al. ${ }^{25}$ have attributed NP elongation to melting and creep deformation induced by an overpressure due to differences in volume expansion and compressibility of the metallic NP and insulating $\mathrm{SiO}_{2}$ matrix. A stress-driven deformation of the $\mathrm{SiO}_{2}$ matrix due to SHII-induced in-plane strain has also been suggested as a potential elongation mechanism. ${ }^{34}$ The latter leads to the well-known "ion hammering" effect, ${ }^{17,51}$ causing the anisotropic expansion of both bulk $\mathrm{SiO}_{2}$ (Ref. 52) and colloidal $\mathrm{SiO}_{2}$ (Ref. 53) 

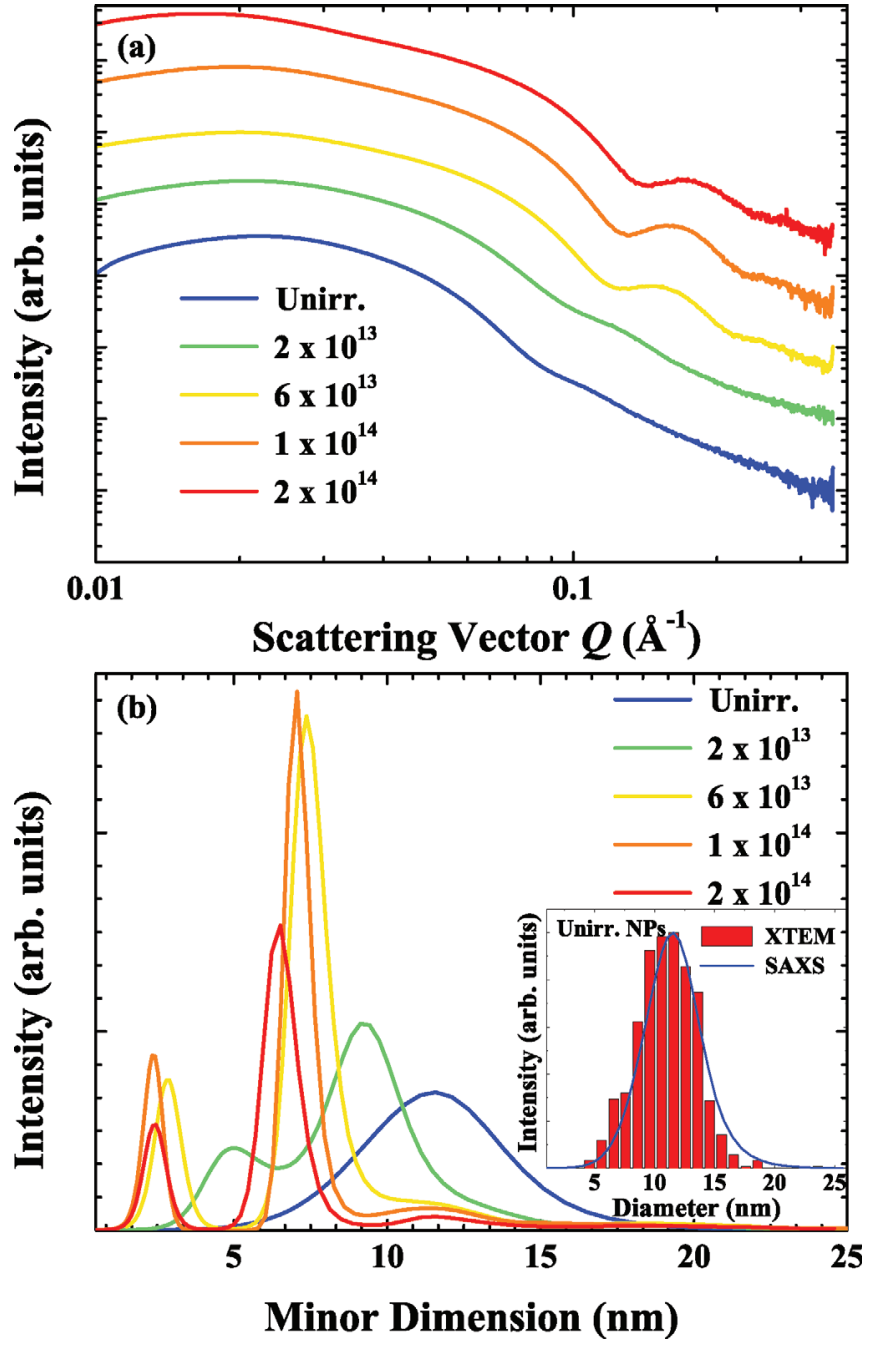

FIG. 3. (Color online) (a) Background corrected SAXS scattering intensity as a function of scattering vector $Q$, and (b) the corresponding minor dimension distributions for Co NPs for $89 \mathrm{MeV}$ Au ion irradiation at different fluences $\left(\mathrm{cm}^{-2}\right)$. The inset compares XTEM and SAXS distributions for the unirradiated sample.

perpendicular to the incident ion direction. The lack of NP elongation in the absence of a sufficiently thick surrounding matrix $^{27}$ supports this theory. Calculations using a viscoelastic model,${ }^{54}$ however, show that the strain generated by the incident ions in the $\mathrm{SiO}_{2}$ matrix alone is insufficient to deform the Co NPs. Furthermore, the strain mechanism cannot explain the observed $\mathrm{S}_{\mathrm{e}}$-dependent saturation of the NP width.

As discussed above, the correlation between the minor dimension and the molten ion track diameter shown in Fig. 4 suggests that the elongation is confined by the ion track. Various metal-specific differences in NP elongation following SHII have been recently discussed ${ }^{50}$ where the thermodynamic properties of both the matrix and metal were shown to be intrinsic to the shape transformation process. As above, the maximum saturated width of an elongated NP was limited by the diameter of the molten ion track while the minimum size for elongation was governed by the energy density required for vaporization. The $\mathrm{S}_{\mathrm{e}}-$ dependent elongation of Co NPs presented here is consist-

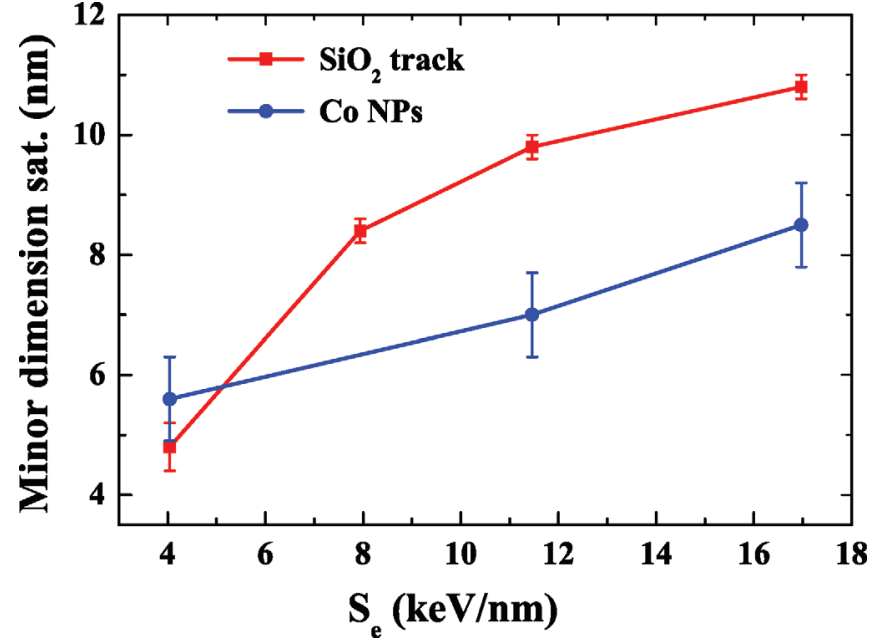

FIG. 4. (Color online) Saturated minor dimension for Co NPs and $\mathrm{SiO}_{2}$ ion track diameter as a function of electronic stopping power in $\mathrm{SiO}_{2}$.

ent with the model proposed in the aforementioned work, such that the Co NPs melt and flow, the latter within the molten ion track formed in the matrix.

\section{B. Local Structure}

The atomic environment of the Co NPs as a function of SHII energy and fluence was determined from XANES analysis, an example of which is shown in Fig. 5(a). Prior to SHII, the NPs were fcc in phase. At low fluences before any significant change in NP shape, the fcc-to-hcp phase transformation was observed, consistent with our previous report. ${ }^{23}$ Figure 5(a) shows that with increasing fluence the NP spectra undergo further changes relative to the unirradiated and bulk spectra, including a decrease in intensity of the feature at $7710 \mathrm{eV}$; a smearing of the features at 7726 , 7730 , and $7760 \mathrm{eV}$; and a shift of the absorption edge to higher energy. All such changes are characteristic of oxide formation. ${ }^{55}$ A linear combination fit of the XANES region was performed to quantify the fraction of Co in metallic and oxidized phases. The standard for the former was hcp Co while that for the latter was the as-implanted, NP-free sample. ${ }^{56}$ The metallic and oxide fractions are reported in Fig. 5(b) as functions of SHII fluence and energy. After high fluence irradiation, Co NP dissolution is manifested by the decrease in the metallic Co atom fraction and the concomitant increase in the oxidized Co atom fraction. Figure 5(b) demonstrates that the dissolution rate is enhanced with an increase in electronic stopping power and, thus, the process is not ballistic.

The XTEM, SAXS, and XANES results presented herein clearly demonstrate that the volume fraction of NPs embedded in the $\mathrm{SiO}_{2}$ is not conserved upon irradiation in contrast to previous reports. ${ }^{25,40-42}$ As we recently showed elsewhere, ${ }^{50}$ the deposited energy density of spherical NPs scales as the inverse square of the NP diameter. When the deposited energy density exceeds the vaporization energy, the NP is dissociated via vaporization. Small NPs are thus 

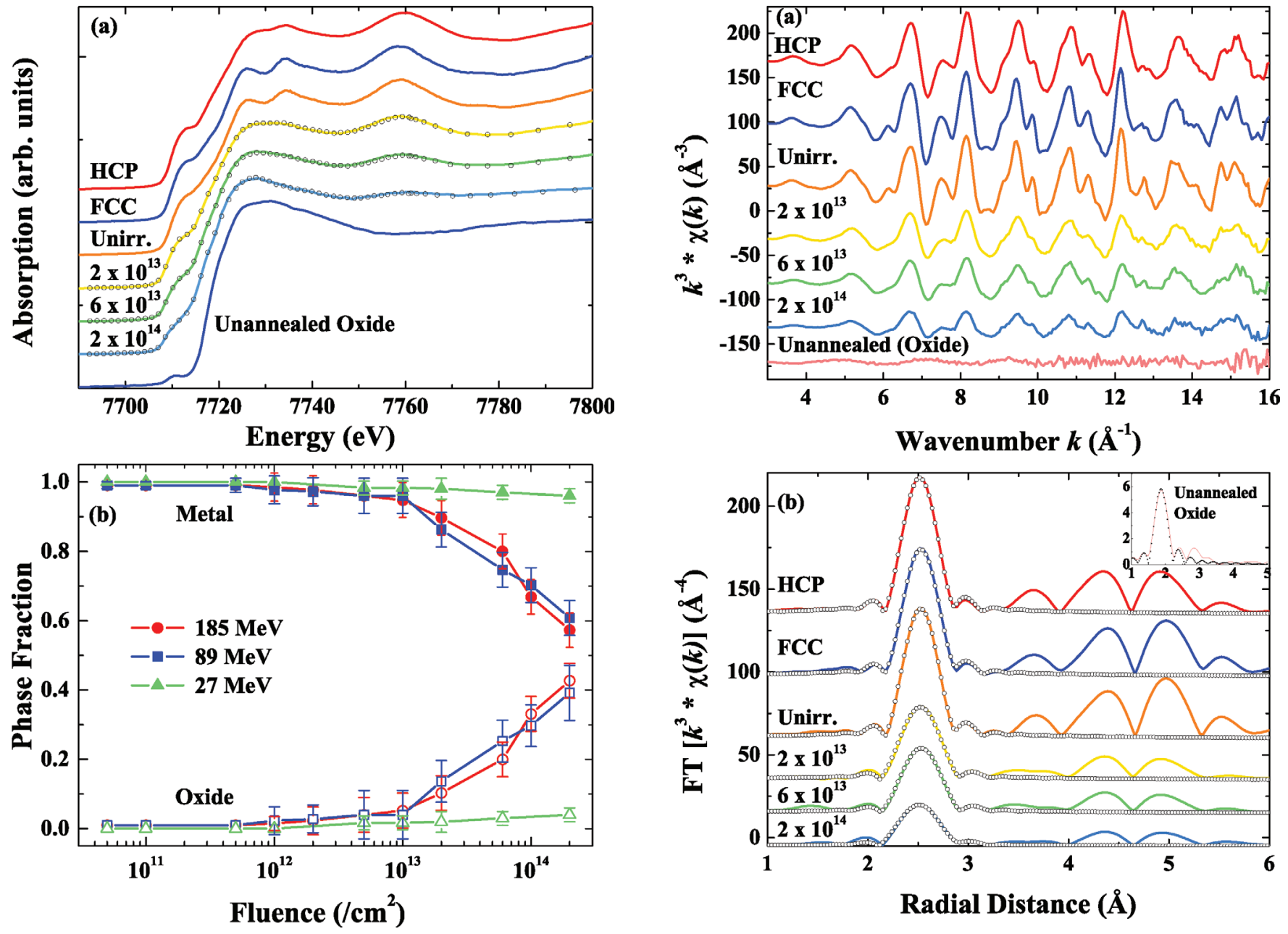

FIG. 5. (Color online) (a) XANES spectra for bulk standards and NP samples for $185 \mathrm{MeV}$ Au ion irradiation as a function of fluence $\left(\mathrm{cm}^{-2}\right)$. Open circles in (a) represent linear combination fits to experimental data with oxide and metal standards; (b) shows the metallic and oxide fractions determined from the XANES analysis.

more susceptible to dissolution than their larger counterparts. Similarly, the deposited energy density of elongated NPs scales as the inverse square of the NP width. Spherical NPs below the threshold diameter and elongated NPs below the saturation width are unstable under SHII and are vaporized as a result of the interaction with an incident ion.

Structural parameters for the Co NPs were determined from EXAFS. Figure 6(a) displays the $k^{3}$-weighted EXAFS for NPs irradiated at $185 \mathrm{MeV}$ as a function of fluence. The amplitude of the EXAFS signal decreases as the ion fluence increases. Figure 6(b) shows the corresponding phase-corrected FT spectra with fits to the experimental data superimposed. Prior to SHII, the NP spectrum is comparable to the fcc standard as expected for NPs of this large size. Upon irradiation, changes in the amplitude are readily observable. No $\mathrm{Co}-\mathrm{O}$ contribution at $\sim 1.8 \AA$ is apparent in the spectra, even for samples with $50 \%$ oxide fraction, given that $\mathrm{O}$ is a weak scatterer and the Co-O bonding in the amorphous matrix is highly disordered. Under such conditions, a more reliable quantification of the oxide fraction was achieved with XANES, as described previously.

The evolution of the $D W F, B L, C_{3}$, and $C N$ determined from the EXAFS analysis for the different SHII energy and fluence combinations is shown in Fig. 7(a)-7(d), respectively. Prior to SHII, the NP structural parameters are similar to bulk fcc $\mathrm{Co}$ as anticipated. For a given irradiation energy, Fig. 7 readily demonstrates the progressive structural modification of the Co NPs as a function of fluencethe increase in $D W F$ and decrease in $C N, B L$, and $C_{3}$ are all consistent with the SHII-induced decrease in NP size, the latter first shown in Fig. 1. As the NP size decreases, the influence of the surface and finite-size effects necessarily increases. ${ }^{56}$ For a given irradiation fluence, Fig. 7 also demonstrates that the structural modifications are more rapid with an increase in irradiation energy or, equivalently, electronic stopping power. Higher $S_{e}$ values yield higher temperatures in both the metal and matrix and, as a consequence of the latter, a greater ion track diameter. All such increases lead to a more rapid change in structural parameters. 

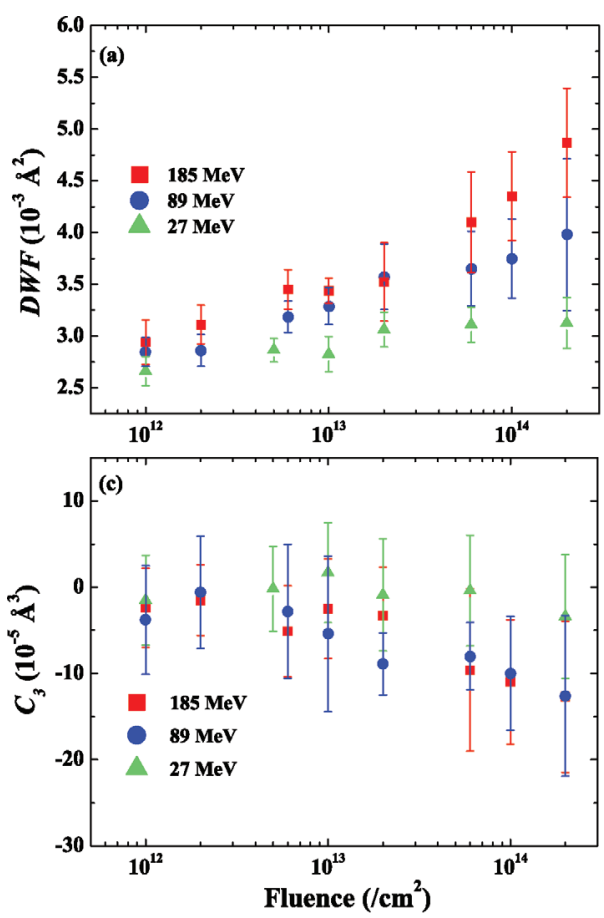
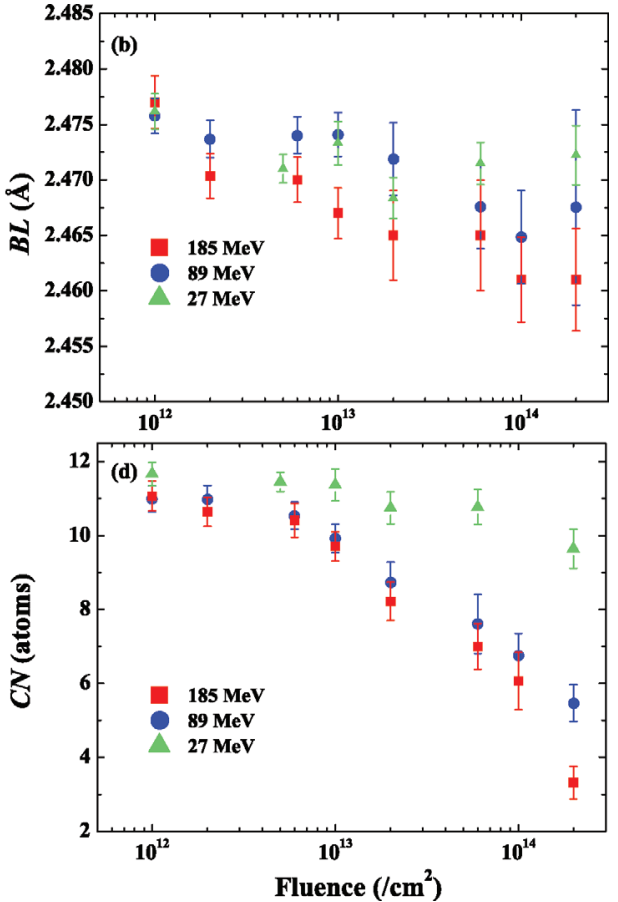

FIG. 7. (Color online) Results from the EXAFS analysis of the first nearest neighbor shell (a) $D W F$, (b) $B L$, (c) $C_{3}$, and (d) $C N$ for irradiated samples as a function of SHII energy and fluence.

\section{CONCLUSION}

In summary, shape, size, and structural changes in $\mathrm{Co}$ NPs embedded in $\mathrm{SiO}_{2}$ and subjected to SHII have been quantified. XTEM and SAXS analysis revealed NPs below a threshold size remained spherical in shape and progressively dissolved in the matrix with increasing fluence. NPs above the threshold size transformed into nanorods with their major dimension parallel to the incident ion direction. The nanorod width saturated at a value that increased with electronic stopping power and was directly correlated to the width of the molten ion track in $\mathrm{SiO}_{2}$. The NP structural parameters were determined by XAS as a function of SHII energy and fluence. Changes included a decreased $B L, C_{3}$, and $C N$ and an increased $D W F$, all consistent with the observed reduction in NP size. Our results demonstrate the usefulness of SHII as a means of fabricating aligned, elongated NPs with specific dimensions and structure.

\section{ACKNOWLEDGMENTS}

D.J.S. wishes to thank Dr J. Bradby and Dr. S. Ruffell for their aid in the preparation of the manuscript. This work was financially supported by the Australian Synchrotron and the Australian Research Council with access to equipment provided by the Australian Nanofabrication Facility. ChemMatCARS Sector 15 is principally supported by the NSF/ DOE under Grant No. NSF/CHE-0822838. Use of the Advanced Photon Source was supported by the U.S. DOE, Office of Science, Office of Basic Energy Sciences, under Contract No. DE-AC02-06CH11357.

${ }^{1}$ C. Burda, X. B. Chen, R. Narayanan, and M. A. El-Sayed, Chem. Rev. 105, 1025 (2005).

${ }^{2}$ K. L. Kelly, E. Coronado, L. L. Zhao, and G. C. Schatz, J. Phys. Chem. B 107, 668 (2003).
${ }^{3}$ P. Mulvaney, Langmuir 12, 788 (1996).

${ }^{4}$ M. C. Ridgway, C. J. Glover, G. J. Foran, and K. M. Yu, J. Appl. Phys. 83, 4610 (1998).

${ }^{5}$ M. C. Ridgway, C. J. Glover, K. M. Yu, G. J. Foran, C. Clerc, J. L. Hansen, and A. N. Larsen, Phys. Rev. B 61, 12586 (2000).

${ }^{6}$ W. J. Weber, Nucl. Instrum. Methods Phys. Res. B 166, 98 (2000).

${ }^{7}$ K. Nordlund, M. Ghaly, R. S. Averback, M. Caturla, T. D. de la Rubia, and J. Tarus, Phys. Rev. B 57, 7556 (1998).

${ }^{8}$ B. Johannessen, P. Kluth, D. J. Llewellyn, G. J. Foran, D. J. Cookson, and M. C. Ridgway, Phys. Rev. B 76, 184203 (2007).

${ }^{9}$ P. Kluth, B. Johannessen, G. J. Foran, D. J. Cookson, S. M. Kluth, and M. C. Ridgway, Phys. Rev. B 74, 014202 (2006).

${ }^{10}$ D. J. Sprouster, R. Giulian, L. L. Araujo, P. Kluth, B. Johannessen, N. Kirby, K. Nordlund, and M. C. Ridgway, Phys. Rev. B 81, 155414 (2010).

${ }^{11}$ G. Rizza, H. Cheverry, T. Gacoin, A. Lamasson, and S. Henry, J. Appl. Phys. 101, 014321 (2007).

${ }^{12}$ R. L. Fleischer, P. B. Price, and R. M. Walker, J. Appl. Phys. 36, 3645 (1965).

${ }^{13}$ D. Lesueur and A. Dunlop, Radiat. Eff. Defects Solids 126, 163 (1993).

${ }^{14}$ A. E. Volkov and V. A. Borodin, Nucl. Instrum. Methods Phys. Res. B 146, 137 (1998).

${ }^{15}$ Z. G. Wang, C. Dufour, E. Paumier, and M. Toulemonde, J. Phys.: Condens. Matter 6, 6733 (1994).

${ }^{16}$ M. Toulemonde, C. Dufour, and E. Paumier, Phys. Rev. B 46, 14362 (1992).

${ }^{17}$ S. Klaumunzer, M. D. Hou, and G. Schumacher, Phys. Rev. Lett. 57, 850 (1986).

${ }^{18}$ A. Benyagoub, Phys. Rev. B 72, 094114 (2005).

${ }^{19}$ W. Wesch, A. Kamarou, and E. Wendler, Nucl. Instrum. Methods Phys. Res. B 225, 111 (2004).

${ }^{20}$ C. S. Schnohr, P. Kluth, A. P. Byrne, G. J. Foran, and M. C. Ridgway, Phys. Rev. B 77, 073204 (2008).

${ }^{21}$ A. Meftah, F. Brisard, J. M. Costantini, E. Dooryhee, M. Hageali, M. Hervieu, J. P. Stoquert, F. Studer, and M. Toulemonde, Phys. Rev. B 49, 12457 (1994).

${ }^{22}$ G. Rizza, A. Dunlop, and A. Dezellus, Nucl. Instrum. Methods Phys. Res. B 256, 219 (2007).

${ }^{23}$ D. J. Sprouster, R. Giulian, C. S. Schnohr, L. L. Araujo, P. Kluth, A. P. Byrne, G. J. Foran, B. Johannessen, and M. C. Ridgway, Phys. Rev. B 80, 115438 (2009).

${ }^{24}$ G. Rizza, E. A. Dawi, A. M. Vredenberg, and I. Monnet, Appl. Phys. Lett. 95, 043105 (2009). 
${ }^{25}$ C. D’Orleans, J. P. Stoquert, C. Estournes, C. Cerruti, J. J. Grob, J. L. Guille, F. Haas, D. Muller, and M. Richard-Plouet, Phys. Rev. B 67, 220101 (2003).

${ }^{26}$ A. Oliver, J. A. Reyes-Esqueda, J. C. Cheang-Wong, C. E. Roman-Velazquez, A. Crespo-Sosa, L. Rodriguez-Fernandez, J. A. Seman, and C. Noguez, Phys. Rev. B 74, 245425 (2006).

${ }^{27}$ J. J. Penninkhof, T. van Dillen, S. Roorda, C. Graf, A. van Blaaderen, A. M. Vredenberg, and A. Polman, Nucl. Instrum. Methods Phys. Res. B 242, 523 (2006).

${ }^{28}$ K. Awazu, X. M. Wang, M. Fujimaki, J. Tominaga, H. Aiba, Y. Ohki, and T. Komatsubara, Phys. Rev. B 78, 054102 (2008).

${ }^{29}$ E. A. Dawi, G. Rizza, M. P. Mink, A. M. Vredenberg, and F. Habraken, J. Appl. Phys. 105 (2009)

${ }^{30}$ R. Giulian, P. Kluth, L. L. Araujo, D. J. Sprouster, A. P. Byrne, D. J. Cookson, and M. C. Ridgway, Phys. Rev. B 78, 125413 (2008).

${ }^{31}$ R. Giulian, F. Kremer, L. L. Araujo, D. J. Sprouster, P. Kluth, P. F. P. Fichtner, A. P. Byrne, and M. C. Ridgway, Phys. Rev. B 82, 113410 (2010).

${ }^{32}$ P. Kluth, R. Giulian, D. J. Sprouster, C. S. Schnohr, A. P. Byrne, D. J. Cookson, and M. C. Ridgway, Appl. Phys. Lett. 94, 113107 (2009).

${ }^{33}$ Y. K. Mishra, F. Singh, D. K. Avasthi, J. C. Pivin, D. Malinovska, and E. Pippel, Appl. Phys. Lett. 91, 063103 (2007).

${ }^{34}$ S. Roorda, T. van Dillen, A. Polman, C. Graf, A. van Blaaderen, and B. J. Kooi, Adv. Mater. 16, 235 (2004).

${ }^{35}$ M. C. Ridgway, P. Kluth, R. Giulian, D. J. Sprouster, L. L. Araujo, C. S. Schnohr, D. J. Llewellyn, A. P. Byrne, G. J. Foran, and D. J. Cookson, Nucl. Instrum. Methods Phys. Res. B 267, 931 (2009).

${ }^{36}$ T. van Dillen, A. van Blaaderen, and A. Polman, Mater. Today 7, 40 (2004).

${ }^{37}$ S. H. Sun and C. B. Murray, J. Appl. Phys. 85, 4325 (1999).

${ }^{38}$ Q. A. Pankhurst, J. Connolly, S. K. Jones, and J. Dobson, J. Phys. D: Appl. Phys. 36, R167 (2003).

${ }^{39}$ H. Zeng, M. Zheng, R. Skomski, D. J. Sellmyer, Y. Liu, L. Menon, and S. Bandyopadhyay, J. Appl. Phys. 87, 4718 (2000).
${ }^{40}$ C. D’Orleans, C. Cerruti, C. Estournes, J. J. Grob, J. L. Guille, F. Haas, D. Muller, M. Richard-Plouet, and J. P. Stoquert, Nucl. Instrum. Methods Phys. Res. B 209, 316 (2003).

${ }^{41}$ C. D’Orleans, J. P. Stoquert, C. Estournes, J. J. Grob, D. Muller, C. Cerruti, and F. Haas, Nucl. Instrum. Methods Phys. Res. B 225, 154 (2004).

${ }^{42}$ C. D'Orleans, J. P. Stoquert, C. Estournes, J. J. Grob, D. Muller, J. L. Guille, M. Richard-Plouet, C. Cerruti, and F. Haas, Nucl. Instrum. Methods Phys. Res. B 216, 372 (2004).

${ }^{43}$ J. F. Ziegler, J. P. Beirsack, and U. Littmark, The Stopping and Range of Ions in Matter (Pergamon Press, New York, 1985).

${ }^{44}$ C. S. Tsao and T. L. Lin, J. Appl. Crystallogr. 30, 353 (1997).

${ }^{45}$ B. Ravel and M. Newville, J. Synchrot. Radiat. 12, 537 (2005).

${ }^{46}$ M. Newville, J. Synchrot. Radiat. 8, 322 (2001).

${ }^{47}$ J. J. Rehr and R. C. Albers, Rev. Mod. Phys. 72, 621 (2000).

${ }^{48}$ A. Guinier and G. Fournet, Small-Angle Scattering of X-rays (Wiley, New York, 1955)

${ }^{49}$ P. Kluth, C. S. Schnohr, O. H. Pakarinen, F. Djurabekova, D. J. Sprouster, R. Giulian, M. C. Ridgway, A. P. Byrne, C. Trautmann, D. J. Cookson, K. Nordlund, and M. Toulemonde, Phys. Rev. Lett. 101, 175503 (2008).

${ }^{50}$ M. C. Ridgway, R. Giulian, D. J. Sprouster, P. Kluth, L. L. Araujo, D. J. Llewellyn, and A. P. Byrne, F. Kremer, P. F. P. Fichtner, G. Rizza, H. Amekura and M. Toulemonde: Phys. Rev. Lett. 106, 095505 (2011).

${ }^{51}$ H. Trinkaus and A. I. Ryazanov, Phys. Rev. Lett. 74, 5072 (1995).

${ }^{52}$ S. Klaumunzer, Nucl. Instrum. Methods Phys. Res. B 225, 136 (2004).

${ }^{53}$ T. van Dillen, A. Polman, W. Fukarek, and A. van Blaaderen, Appl. Phys. Lett. 78, 910 (2001)

${ }^{54}$ S. Klaumunzer, Nucl. Instrum. Methods Phys. Res. B 244, 1 (2006).

${ }^{55}$ L. A. Grunes, Phys. Rev. B 27, 2111 (1983).

${ }^{56}$ D. J. Sprouster, R. Giulian, L. L. Araujo, P. Kluth, B. Johannessen, D. J. Cookson, G. J. Foran, and M. C. Ridgway, J. Appl. Phys. 107, 014313 (2010). 